Williams et al._https://doi.org/10.51681/1.112

\title{
Introducing a Multidisciplinary Framework of Positive Sexuality
}

\author{
D J Williams, PhD \\ Idaho State University and Center for Positive Sexuality \\ Jeremy N. Thomas, PhD \\ Idaho State University and Center for Positive Sexuality \\ Emily E. Prior, MA \\ Center for Positive Sexuality \\ Wendy Walters, $\mathrm{PhD}$ \\ Central Washington University
}

\section{Introduction}

In this article we will introduce the concept of sex-positivity, or positive sexuality, before proposing a multidisciplinary framework that identifies key dimensions of positive sexuality as an approach to understanding and addressing a full range of sexuality topics and issues. Indeed, the Journal of Positive Sexuality focuses on this theme and its potential theoretical and practical benefits.

Four decades ago while writing about sexual variation, Vern Bullough (1976) referred to societies as being more or less sex-positive or sex-negative. Since then, the term sex-positive has been debated from diverse, and sometimes oppositional, theoretical positions. While there are many who may commonly assume that sex-positivity simply means having a pro-sex stance on various socio-sexual issues, we believe that sex-positivity, or positive sexuality, may be a more fitting term that perhaps better encapsulates notions of diversity, empowerment, and choice. Sexnegative perspectives tend to frame sexuality and sexual practices primarily as risky, difficult to manage, and perhaps adversarial; while variations of sex-positivity seem to acknowledge risks and concerns yet also emphasize the importance of sexual pleasure, freedom, and diversity.

A social climate of sex-negativity has been linked to numerous social problems, including homophobia, sexism, ageism, racism, marginalization of sexual minorities, deficiencies in providing sex education, and ineffective policies in addressing sexual offending (Glickman, 2000; Williams, Prior, \& Wegner, 2013). Therefore, we believe that there may be considerable value, both theoretically and practically, in exploring positive sexuality as an approach to addressing a range of diverse sexuality issues.

Scholars and professionals likely have their own definitions and variations of what sex-positive means. We see this as healthy and productive. While sex-positivity may be understood differently among scholars and professionals, it is likely that some of the key ingredients of positive sexuality, including those mentioned above, are consistent across definitions. Moreover, 
Williams et al._https://doi.org/10.51681/1.112

we further propose that a positive sexuality framework may be beneficial in helping to guide sex research, practice, and education.

\section{Key Dimensions of a Positive Sexuality Framework}

After thoroughly considering a multidisciplinary social and behavioral science literature, we propose eight key dimensions that provide a basic structure for a positive sexuality framework. This framework may be helpful in addressing a wide range of topics and issues pertaining to sexuality, and the dimensions should be very familiar to most readers.

\section{"Positive" Refers to Strengths, Wellbeing, and Happiness}

Traditional methods of addressing a vast range of social issues focus on deficits. Typically, assessments are conducted, problems and deficits are identified, and interventions are prescribed in order to correct such deficits. This process has been, and still is, common across multiple disciplines, including education, health and medicine, psychology, counseling, and social work. However, for well over two decades, scholars have recognized that specific individuals, families, and communities have numerous inherent strengths (for a review, see Saleebey, 2009). These strengths can be identified and then utilized to resolve problems. A strengths-approach requires a shift in how we relate to people - we strive to empower them based on their existing capabilities. The task is not to identify what people are doing wrong and then to add something external to correct it (deficit approach), but to recognize the things that people do, or have done, well, along with the underlying, contributing strengths that allow for success. We can then help people apply their particular strengths to resolve problems. Our purpose, then, is to nourish and support people's interests, motivations, resources, and emotions in helping them meet their needs and goals, thus leading to more happiness and better quality of life (Saleebey, 2009).

At the same time that social workers and counselors were beginning to develop a strengths-based perspective, Martin Seligman and others in psychology were conducting research on characteristics and attributes that bring happiness and satisfaction to people. They realized the immense value in learning about factors and conditions that contribute to people thriving, achieving success, feeling fulfilled, and attaining well-being. Their pioneering work led to the emergence of positive psychology as a new area of inquiry, and positive psychology has quickly grown and flourished (see Linley, Joseph, Harrington, \& Wood, 2006).

For us, positive sexuality, similar to positive psychology and a strengths perspective, includes the recognition that people have an assortment of personal strengths and also unique sexualities. People are capable of drawing from their existing strengths to resolve problems and be happier and more fulfilled, including developing their sexual identities and expressing their sexuality. Positive sexuality, then, is concerned with how people are, or can be, happy and fulfilled with their unique sexualities and sexual expression, which contributes to their overall wellbeing and quality of life. 
Williams et al._https://doi.org/10.51681/1.112

\section{Individual Sexuality is Unique and Multifaceted}

Positive sexuality also begins with the recognition that each person's sexuality is unique and multifaceted. Drawing on the World Health Organization's (WHO, 2006) definition, we observe that sexuality involves a diverse array of aspects including roles and identities, preferences and orientations, relationships and activities, pleasures and desires, scripts and fantasies, as well as values and beliefs. These aspects are shaped by the "interaction of biological, psychological, social, economic, political, cultural, ethical, legal, historical, religious and spiritual factors" ( $p$. $5)$.

One of the implications of this is that sexuality is shaped by factors both internal and external to the self. Hence, people often experience some aspects of their sexuality as relatively given and fixed, while other aspects may be experienced as much more fluid and malleable (Diamond, 2009). It is important to understand, though, that what is fixed and what is fluid varies significantly both from person to person as well as across the life course as people not only make conscious choices to change their sexuality, but also as they inhabit new contexts and participate in new situations that inevitably also lead to change (Sassler, 2010).

What we discover, then, is that each person has a unique sexual history that contributes to, and helps provide, that person with a unique sexual narrative (Plummer, 1995). In turn, most people find that these narratives form an integral part of who they are, both through the interaction that these narratives have with other characteristics and dimensions of the self, as well as through the role that these narratives play in the development of a person's overall sense of identity (Brottoa, Heiman, \& Tolman, 2009). Accordingly, positive sexuality not only begins with the recognition that each person's sexuality is unique and multifaceted, but also with an appreciation of the ways that each person's sexuality contributes to the whole of who that person is.

\section{Positive Sexuality Embraces Multiple Ways of Knowing}

Sexuality has been explored and interpreted from diverse disciplines, epistemologies, methods, and theoretical frameworks. Positivist, postpositivist, critical, postmodern, and poststructural approaches now shape the production of knowledge across many disciplines. More than ever before, scholars are recognizing the value in utilizing a wide range of methodological approaches to more thoroughly understand their topics. Each approach, of course, may have specific scholarly criteria associated with it and will yield unique understandings. Indeed, over a dozen years ago, Gergen (2001) explored how multiple and diverse methods may coexist to enrich and revitalize psychological science. Since then, mixed methods research designs are being applied to single studies with much more frequency. Also, far more methodological diversity among scholars is acknowledged and embraced. In discussing "the queering of anarchism," Shannon and Willis (2010) used the term theoretical polyamory to suggest that drawing from multiple theories is especially valuable in better understanding and addressing complexities of the politics associated with institutionalized domination and control. At the same time, newer artistic methods of inquiry, referred to as creative analytic practice (Richardson, 2000), are regularly used across a range of disciplines. Regarding positive sexuality, we believe there are substantial benefits to welcoming a full range of diverse research approaches to learn how people can be empowered and fulfilled regarding their sexuality and wellbeing.

Journal of Positive Sexuality, Vol. 1, February 2015 (C) 2015 Journal of Positive Sexuality-Center for Positive Sexuality 
Williams et al._https://doi.org/10.51681/1.112

\section{Positive Sexuality Reflects Professional Ethics}

Most professions that interact with the public have a code of ethics to guide decision-making, and in particular, to prevent actions based on self-interest, and to prevent discrimination and injustice. For example, the American Bar Association and the American Institute of Certified Public Accountants require putting clients first, and accountants have the added utilitarian requirement of serving the public good ahead of serving their clients.

In the helping professions, there are specific ethical principles and formal codes of conduct that allow for the expression of self without fear of discrimination. According to the American Psychological Association (2010), the first ethical principle of the profession is that psychologists should not only do no harm, but they should strive to benefit those with whom they work in any setting, including research, teaching, and clinical practice. Psychologists are required to respect "cultural, individual, and role differences" among people (p. 4). The Code of ethics of the National Association of Social Workers (NASW, 2008) argues against self-interest to the point of offering pro-bono work so as to benefit others, and states that social workers not only recognize and respect differences, but seek out those differences. Social workers are admonished to "obtain education about and seek to understand the nature of social diversity and oppression" with respect to numerous aspects of diversity, including sex, sexual orientation, gender identity and expression (p. 3). Other helping professions, including counseling (American Counseling Association, 2005) and medicine (American Medical Association, 1996), also value human diversity, client self-determination, cultural sensitivity, and social justice.

Positive sexuality is consistent with established professional ethical principles and seeks to protect against self-interest and discrimination. Positive sexuality also promotes what is just and right; that is, honoring the voice, needs, choices, experiences, and life of every individual.

\section{Positive Sexuality Promotes Open, Honest Communication}

Being sex positive means going beyond basic reproductive biology and being free to discuss a full spectrum of sexual attitudes and behaviors. Not only does this include communicating one's needs and wants from a sexual perspective, but also recognizing that communication and negotiation are essential to positive sexual interactions and outcomes. Even though open communication about sex is not the status quo in current American culture, many books and articles, both in pop culture and in academia, discuss good communication as being the key to a happy and healthy sex life (i.e., Noland, Manning, \& MacLennan, 2010; Shpancer, 2014).

It is also important to note that open communication about other topics that may or may not be directly related to sex per se should be encouraged. Allowing for freedom of language, concepts, and ideas that may differ from our own or current social norms can help establish trust and safety that are necessary for personal growth and wellbeing.

\section{Positive Sexuality is Humanizing}


A sex positive approach acknowledges diverse problems associated with sexuality and seeks to help resolve them, but it does not use language that devalues people. While it is true that sometimes people can engage in problematic, even atrocious, behavior, people are still human beings. Therefore, our position is that language should not dehumanize or demonize. Terms that contribute to stereotyping, function to establish in-group versus out-group behavior, imply that sexuality and related behaviors are unclean or unhealthy, or stigmatize are not consistent with positive sexuality.

Unfortunately, common discourses allow derogatory language that reflects widespread sexnegativity. This can be easily recognized with terms like "fag" or "whore" but may not be as obvious when terms and phrases like "tranny," "sexual predator," "war on sex," "sissy," "girlie," or "I'm 'clean"” are used. Many of these terms (i.e., tranny, sexual predator, sissy, girlie) are used as identifiers and denote a negative connotation. Some such terms make a clear distinction between acceptable identities (i.e., masculine) and unacceptable identities (i.e., feminine). Other derogatory terms are used to predispose the audience to feel a certain way about a topic (i.e., war on sex) or to clearly distinguish oneself from a group or category that is unwanted (i.e., clean versus dirty).

Sex positive language, on the other hand, seeks to reflect social justice and inclusiveness. Using terms that are inclusive and promote social equity and cultural salience allows all identities and experiences to be respectfully acknowledged.

\section{Positive Sexuality Encourages Peacemaking}

The use of humanizing language is directly connected to the notion of peacemaking. Over the course of his long and distinguished academic career, Hal Pepinski $(2002,2013)$ has drawn from knowledge and wisdom across diverse cultures and social spaces to assemble a theory of peacemaking criminology. While peacemaking applies to community and societal issues (including to promote healing via restorative justice), Pepinski (2013) also sees it as a selfdiscipline. He suggests that people must find their own path to making peace. According to Vitello (2003), people are invited to explore their own personal emotional pain, so that they can then better understand the pain of others, which often contributes to problematic, sometimes even atrocious, behavior. While violence is a reaction to emotional pain and fear, peacemaking centers on compassion and love (Pepinski, 2013). Peace happens when people feel safe and accepted.

Sex-negativity seems to be driven largely by fear, along with perceived threats of actual or potential pain. A common response to such fear and threats is to try to exert control and/or fight. Nevertheless, peace requires self-control, careful listening, empathizing, and learning. In criminology, peacemaking requires an ability to let go of trying to make crime go away, rather than exerting more control (Pepinski, 2013).

Many American social issues, including those involving sexuality, are saturated with warmaking language. We commonly speak of the war on drugs, a need to combat human trafficking, fighting for sexual rights, and so forth. Indeed, the birth of the Journal of Positive Sexuality arose in large part as an attempt to facilitate peace in the midst of ongoing "sex wars" that began way 
back in the 1980s. Thus, an important dimension of positive sexuality is to work to better understand the pain and difficulties of others, work to empower all voices, and to build bridges. The language of positive sexuality should reflect inclusion and peacefulness. In addition to celebrating human diversity, it is important to stay mindful of our common humanness.

\section{Positive Sexuality is Applicable across all Levels of Social Structure}

Because sexuality is an integral part of who we are as people, it thus permeates, directly or indirectly, all aspects of human life. Positive sexuality, then, is relevant across all levels and types of social structure. At the micro level, many individuals struggle with how to understand and express their unique sexualities. The history of sexuality in western society is steeped in negativity, thus many people may feel guilt and shame regarding their sexual curiosities and desires. Many younger people have difficulty establishing their sexual identities or successfully merging their sexuality with other aspects of their identities. At the mezzo level, various sexuality issues are not uncommon, of course, in families and small social groups. Finally, as suggested earlier, positive sexuality may have tremendous potential in helping to resolve important social problems in neighborhoods, organizations and workplaces, and communities (Williams, et al., 2013).

\section{Conclusion}

We believe that the landscape of positive sexuality is fertile, and that it has tremendous potential for theoretical and practical exploration and discovery. Furthermore, we propose that positive sexuality shares several important elements with established social and behavioral sciences. Our positive sexuality framework presented here is an attempt to help map this expansive landscape. Our hope is that a positive sexuality framework can be valuable in understanding and exploring all areas dealing with sexuality, including sex education, sexual identities, sex work and erotic labor, pornography, diverse sexual behaviors and practices, sexual violence prevention, and much more, in an open, inclusive, and humanistic manner.

\section{References}

American Counseling Association. (2005). ACA code of ethics. Alexandria, VA: Author.

American Medical Association. (1996). AMA code of medical ethics. Chicago, IL: Author.

American Psychological Association. (2010). Ethical principles of psychologists and code of conduct. Washington, DC: Author.

Brotto, L. A., Heiman, J. R., \& Tolman, D. L. (2009). Narratives of desire in mid-age women with and without arousal difficulties. Journal of Sex Research, 46, 387-398.

Bullough, V. L. (1976). Sexual variance in society and history. Chicago: University of Chicago Press.
Diamond, L. M. (2009). Sexual fluidity. Cambridge, MA: Harvard University Press.

Gergen, K. J. (2001). Psychological science in a postmodern context. American Psychologist, 56, 803-813.

Glickman, C. (2000). The language of sex-positivity. Electronic Journal of Human Sexuality, 3. Retrieved from: http://www.ejhs.org/volume3/sexpositive.ht $\mathrm{m}$

Linley, A. P., Joseph, S., Harrington, S., \& Wood, A. M. (2006). Positive psychology: Past, present, and (possible) future. Journal of Positive Psychology, 1, 3-16. 
Williams et al._https://doi.org/10.51681/1.112

National Association of Social Workers. (2008). Code of ethics. Washington, DC: Author.

Noland, C., Manning, J., \& Maclennan, J. (Eds.) (2010). Case studies in communication about sex. Newcastle upon Tyne: Cambridge Scholars Publishing.

Pepinski, H. (2002). A struggle to inquire without becoming an un-critical non-criminologist. Critical Criminology, 11, 61-73.

Pepinski, H. (2013). Peacemaking criminology. Critical Criminology, 21, 319-339.

Plummer, K. (1995). Telling sexual stories: Power, change, and social worlds. New York: Routledge.

Richardson, L. (2000). Writing: A method of inquiry. In N. K. Denzin \& Y. S. Lincoln (Eds.), Handbook of qualitative research (pp. 923948). Thousand Oaks, CA: Sage.

Saleebey, D. (Ed.) (2009). The strengths perspective in social work practice ( $5^{\text {th }}$ edi.). Boston, MA: Pearson.

Sassler, S. (2010). Partnering across the life course: Sex, relationships, and mate selection. Journal of Marriage and Family, 72, 557575.

Shannon, D., \& Willis, A. (2006). Theoretical polyamory: Some thoughts on love, thinking, and queering anarchism.

Sexualities, 13, 433-443.

Shpancer, N. (2014). Why aren't we talking to our partners about sex? Psychology Today. Retrieved from:

http://www.psychologytoday.com/blog/insig ht-therapy/201403/why-arent-we-talkingour-partners-about-sex.

Vitello, C. J. (2003). Stalking laws, therapeutic jurisprudence, and peacemaking criminology: A radical law-psychology inquiry. Journal of Forensic Psychology Practice, 3(2), 1-37.

Williams, D J, Prior, E. E., \& Wegner, J. (2013). Resolving problems associated with sexuality: Can a "sex-positive" approach help? Social Work, 58, 273-276.

World Health Organization. (2006). Defining sexual health: Report of a technical consultation on sexual health. Geneva, Switzerland: Author. 